\title{
Minimally invasive aesthetic procedures in young adults
}

This article was published in the following Dove Press journal:

Clinical, Cosmetic and Investigational Dermatology

24 March 201 I

Number of times this article has been viewed

\author{
Uwe Wollina' \\ Alberto Goldman² \\ 'Department of Dermatology \\ and Allergology, Academic Teaching \\ Hospital Dresden-Friedrichstadt, \\ Dresden, Germany; ${ }^{2}$ Clinica \\ Goldman, Porto Alegre, \\ Rio Grande du Sul, Brazil
}

Correspondence: Uwe Wollina Department of Dermatology and Allergology, Academic Teaching Hospital Dresden-Friedrichstadt, Friedrichstrasse 4I, 01067 Dresden, Germany

$\mathrm{Tel}+4935$ I 480 I685

Fax +4935I 480 I219

Email wollina-uw@khdf.de
Abstract: Age is a significant factor in modifying specific needs when it comes to medical aesthetic procedures. In this review we will focus on young adults in their third decade of life and review minimally invasive aesthetic procedures other than cosmetics and cosmeceuticals. Correction of asymmetries, correction after body modifying procedures, and facial sculpturing are important issues for young adults. The implication of aesthetic medicine as part of preventive medicine is a major ethical challenge that differentiates aesthetic medicine from fashion.

Keywords: acne scars, ice pick scars, boxcar scars, fillers

\section{Introduction}

Minimally invasive procedures are more often requested by adult patients of all ages. Nevertheless there are specific needs of different age groups. In two recent reviews, middle-aged women and women older than 60 years have been discussed. ${ }^{1,2}$ In the present paper, we wish to focus on young adult women and men in their third decade of life and address some of the more specific problems in this age group such as the treatment of acne scars, skin laxity, hyperkinetic facial wrinkles, and repair of tissue defects after earlobe piercing.

Although topical treatment may also contribute to improved appearance, we will exclude this from the present review except for medical peels.

\section{Anatomical considerations and early signs of aging}

In the third decade of life, anatomical changes are characterized by the development of maturity. Some of these changes are deeply influenced by pregnancy and lactation; others develop independently. In general, there is good skin elasticity and gravitational folds are uncommon. Hyperactive facial wrinkles are mainly seen on the glabella and forehead.

Minor changes of UV-related skin aging become visible such as pigmentary changes like actinic lentigines in Fitzpatrick skin type I and II. Solar elastosis or dermoheliosis may be seen when outdoor activity meets artificial tanning and heavy smoking. Since smoking has become more popular among younger females than males, we may observe a further increase in the next decade. Indeed, there are a growing number of patients younger than 30 years of age developing basal cell carcinoma. ${ }^{3}$

The majority of patients are characterized by mild signs of aging but this may be comparable to the first grey hair found on ones head. These minor changes mark the transition of youth to initial signs of aging. Nevertheless, minimally aesthetic procedures 
in this particular age group have multiple indications, from improving acne scars and sculpturing facial parts to minimizing the adverse effects of piercing. Anti-aging is part of the spectrum but in contrast to middle-aged patients it does yet not play a major role.

\section{Common aesthetic problems and solutions \\ Acne scars}

Acne has developed from a disease of puberty to a disease expanding from adolescence into adult ages. The most disfiguring element of acne is the development of permanent visible scars. Acne scarring is common but difficult to treat. A descriptive, universally acceptable classification system of atrophic acne scars includes three scar types: ice pick, boxcar, and rolling. Erythema and, less often, pigmentary changes may be associated. ${ }^{4}$

Ice pick and boxcar scars can be improved by several measures including chemical, mechanical, and laser peeling, fractional laser, subcision, dermal fillers, microneedling, excision, and a combination of procedures (Figures 1 and 2). ${ }^{5-10}$

Ablative lasers such as $\mathrm{CO}_{2}$ and Erb:YAG are useful tools in the treatment of acne scars in fair-skinned patients

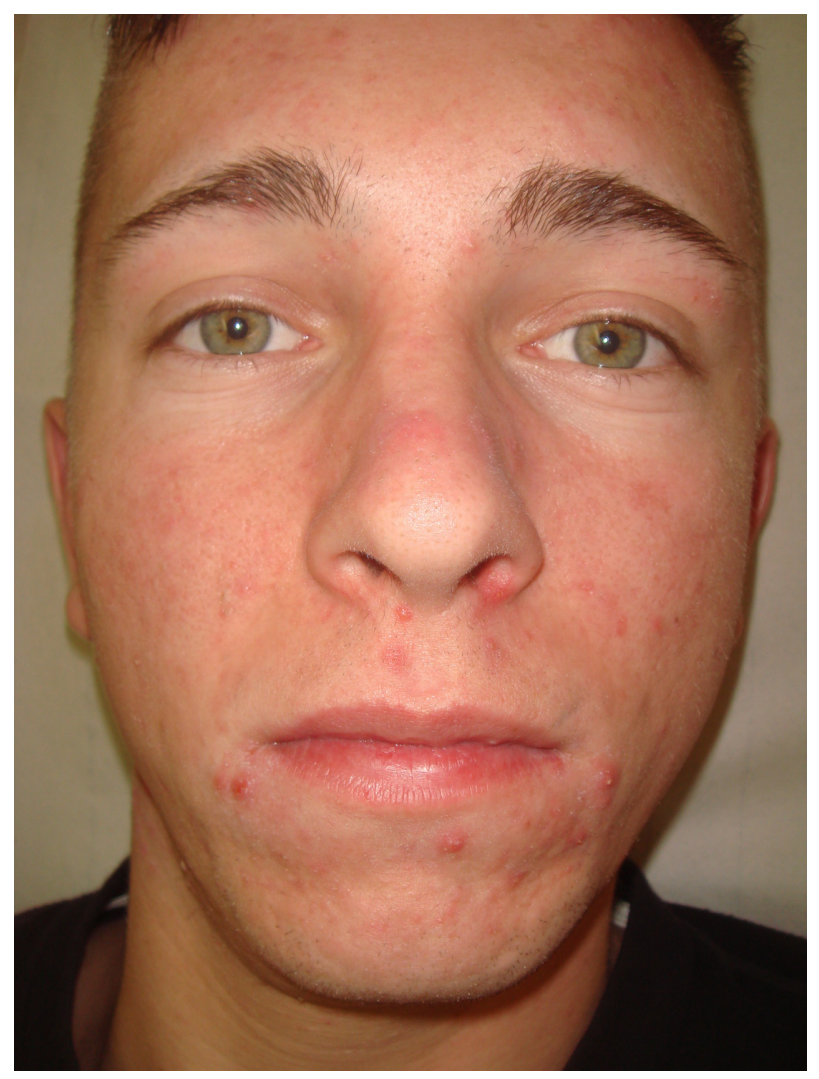

Figure IA Acne treatment by capryloyl salicylic acid peel (22-year-old male) prior to treatment.

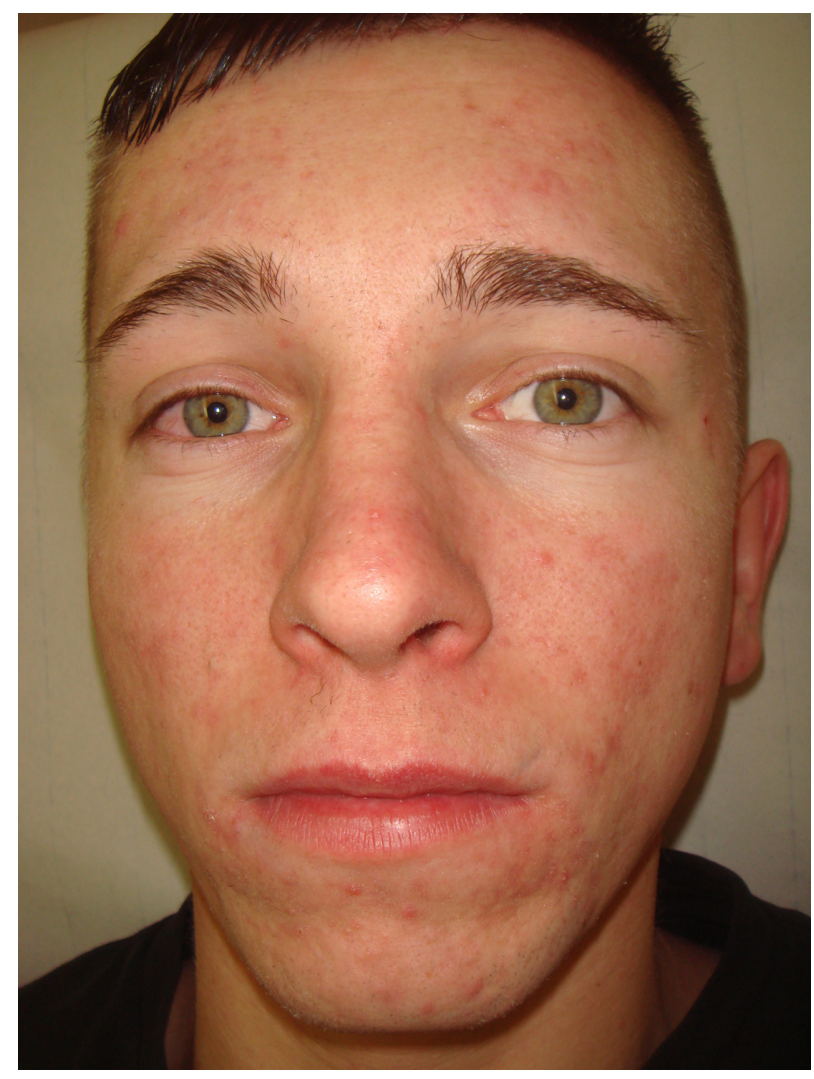

Figure IB Acne treatment by capryloyl salicylic acid peel (22-year-old male) after treatment. Reduction of large inflammatory cysts two weeks after a single treatment with 10\% capryloyl salicylic acid.

only, as they have a higher risk of complications related to pigmentation. Prolonged post-treatment hyperemia is another unwanted side effect. Fractional lasers have less severe side effects but more moderate efficacy compared to ablative devices.

Fractional $\mathrm{CO}_{2}$ laser with a laser fluence from 2.07$4.15 \mathrm{~J} / \mathrm{cm}^{2}$ has been shown to increase tissue repair both clinically and on cytokine levels. ${ }^{11}$ Efficacy and safety of

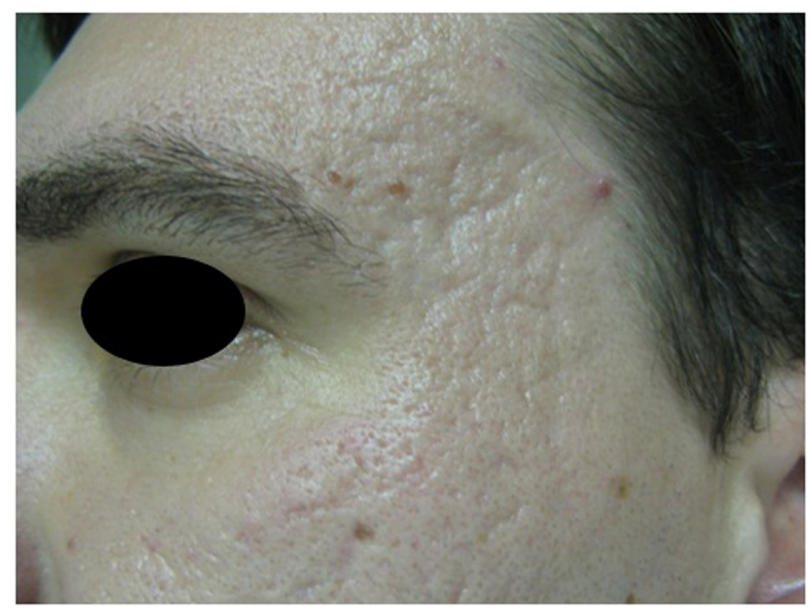

Figure 2A Fractional $\mathrm{CO}_{2}$ laser for acne scars before treatment. 


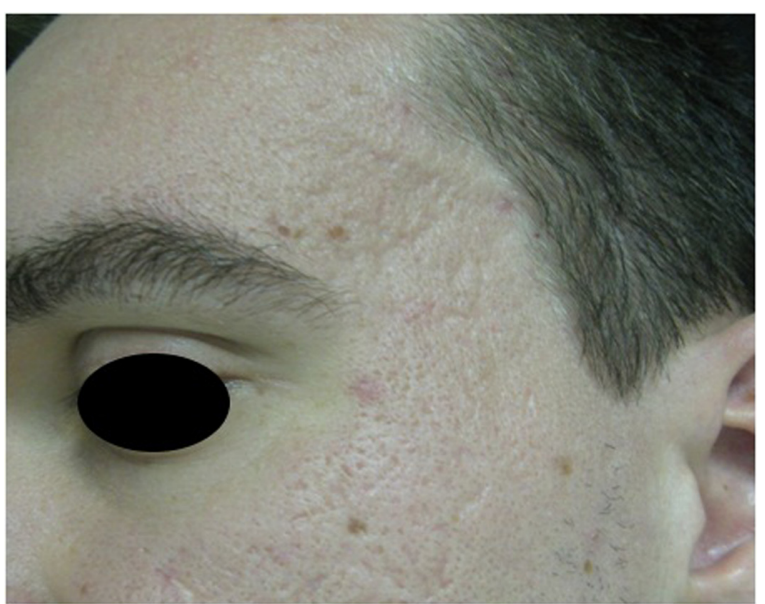

Figure 2B Fractional $\mathrm{CO}_{2}$ laser for acne scars after two laser sessions with marked improvement of skin surface.

an erbium-doped 1,550-nm fractional laser in the treatment of facial acne scars in Fitzpatrick skin types IV to VI was studied in a prospective, single-blind, randomized trial in 15 patients with acne scars. Patients were divided into two groups; one was treated with $10 \mathrm{~mJ}$ and the other with $40 \mathrm{~mJ}$. Five monthly laser sessions were performed. During treatment there was a significant improvement in the acne scarring and overall appearance with no significant difference between the 10 and $40 \mathrm{~mJ}$ groups. Patients were highly satisfied with their results. Significant postinflammatory hyperpigmentation was seen in patients. Pain was significantly higher in darker skin. ${ }^{12}$

More recently, nonablative laser systems have been introduced into acne scar treatment. The nonablative 1,550-nm erbium-doped fractional photothermolysis system has been effectively used for scar treatments in Asian skin, but it seems that several sessions of treatment must be delivered to achieve satisfactory improvement. ${ }^{13}$

Fourteen patients with atrophic acne scars were treated by a combination of subcision and permanent dermal filler injection $\left(\right.$ Artefill $^{\circledR}$ ). Investigator ratings after eight months postprocedure indicated that $96 \%$ of the atrophic acne scars showed some degree of improvement. The majority of patients reported a moderate correction, correlating with a $51 \%-75 \%$ improvement in their acne scars at eight months. No adverse events or side effects were noted in this short study. ${ }^{14}$ Since permanent filler may produce adverse reactions after many years, the risk may not outweigh the benefits in younger adults. Nonpermanent filler such as hyaluronic acid (HA) may be considered, but repeated application will be necessary.

Boxcar scars are mostly treated by excision or ablative procedures. In a recent trial, 24 subjects with punched-out acne scars were treated monthly for two months with four passes of various square pulse Er:YAG laser resurfacing using a $7-\mathrm{mm}$ spot size and a fluence of $0.4 \mathrm{~J} / \mathrm{cm}^{2}$. Subjects were divided into two groups and treated with two different pulse widths: 300 micros (short pulse) and 1,500 micros (extra-long pulse). In the short pulse group, skin smoothness improved significantly whereas in the extra-long pulse group, skin smoothness and scar volume improved significantly from baseline. ${ }^{15}$ For rolling scars, but not icepick scars, the 1,550 nm Erb:Glass fractional laser three times with a 6-week interval showed efficacy. ${ }^{16}$ Subcision is a reliable method for rolling scars. In a trial with 22 patients, subcision showed mild improvement in about $60 \%$ of patients and moderate improvement in about $40 \%$ of them. ${ }^{17}$ Other laser types used successfully to improve acne scars include Erb:YAG and $\mathrm{CO}_{2}$ fractional lasers.

Microneedling is a relatively new and simple procedure for dermatology. In a study from Italy, 32 patients with acne rolling scars were enrolled. Each patient was treated in two sessions. Analysis of the patient photographs and of the degree of irregularity of the skin surface, supported by fast Fourier transformation, showed that after only two sessions, the severity grade of rolling scars in all patients was greatly reduced and there was an overall aesthetic improvement. ${ }^{18}$

The aim of acne scar treatment is to stimulate wound healing and collagen neogenesis. Skin relaxation is addressed by subcision and related methods. It seems that effects can be long-lasting. The usual outcome is an improvement of $25 \%-75 \%$, with most procedures achieving around $50 \%$. Complete resolution is still impossible. ${ }^{19}$

Chemical peeling can be used as an adjunct to acne treatment such as salicylic acid peels, but also for scar treatment. Chemical reconstruction of skin scars (CROSS) is a technique using high concentrations of trichloroacetic acid (TCA) focally on atrophic acne scars to induce inflammation followed by new collagen formation. This can lead to a reduction in the appearance of scars and cosmetic improvement. In an Indian pilot study, CROSS technique using 100\% TCA was investigated for ice pick acne scars. Twelve patients were treated with the CROSS technique, using 100\% TCA, applied with a wooden toothpick, at two weekly intervals for four treatments. More than 50\% improvement was seen in all patients with eight out of ten patients achieving $>70 \%$ improvement. Transient hypopigmentation and hyperpigmentation was an uncommon adverse effect. The CROSS technique with $100 \%$ TCA seems to be a safe, efficacious, cost-effective, and minimally invasive technique for the management of ice pick acne scars in Indian skin. ${ }^{20}$ 
Possible adverse effects of scar treatment include hyperpigmentation, and less commonly, hypopigmentation, particularly in Asian skin. Temporary acneiform eruptions have been seen. Early effective acne therapy is the only way to avoid scarring.

\section{Skin laxity}

Laxity of skin is related to biochemical chances within the connective tissue leading to a decrease of collagen and elastic fibres. Although the process becomes more visible in middleaged subjects, weight loss and pregnancy may be associated with skin laxity also amongst younger patients.

Fine wrinkling around the eyes is often the first sign of facial aging. Whereas crow's feet are caused by muscular activity, a major part of the wrinkling of lower eyelids is the development of skin laxity. Younger females in particular are looking for procedures that are noninvasive and don't cause downtime. For skin tightening in this sensitive area, radiofrequency devices (monopolar or bipolar), laser, or ultra-pulsed light and infrared light devices have been used. $^{21,22}$

One of the therapeutic principles used is dermal remodelling by stimulation of collagen synthesis. This can be achieved by heating the dermal tissue or wounding as with fractioned $\mathrm{CO}_{2}$ or Erb:YAG laser. Peak temperature, total time of exposure, and mechanical stress applied to the skin during the heating process affect the clinical results. Noninvasive radiofrequency and infrared devices seems to be more active on the looser and delicate skin such as eyelids (Figure 3). ${ }^{21}$

Most studies demonstrate an improvement measured by clinical scores, high-frequency ultrasound, or confocal laser microscopy in the range of $30 \%-50 \%$ during one treatment series (Table 1).

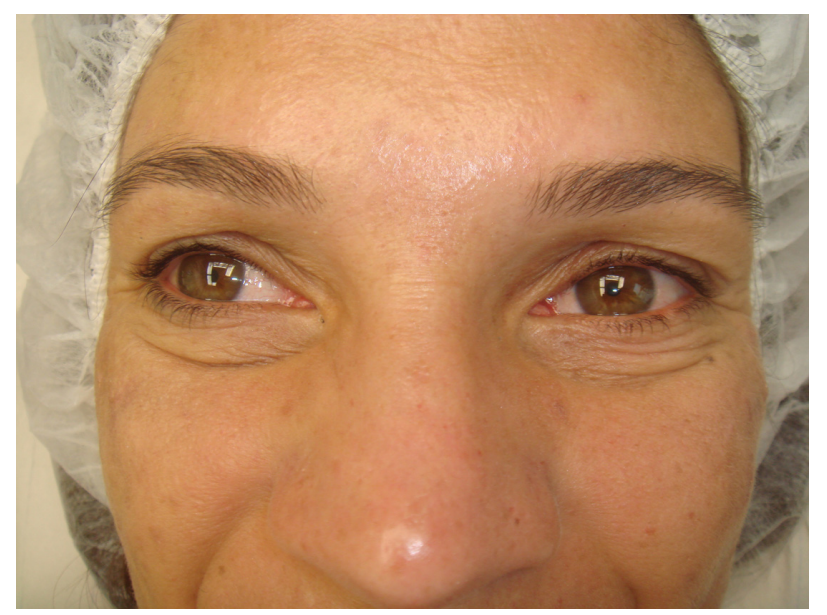

Figure 3A Monopolar radiofrequency treatment of lower eyelids before treatment. The usual treatment series is four to six applications.

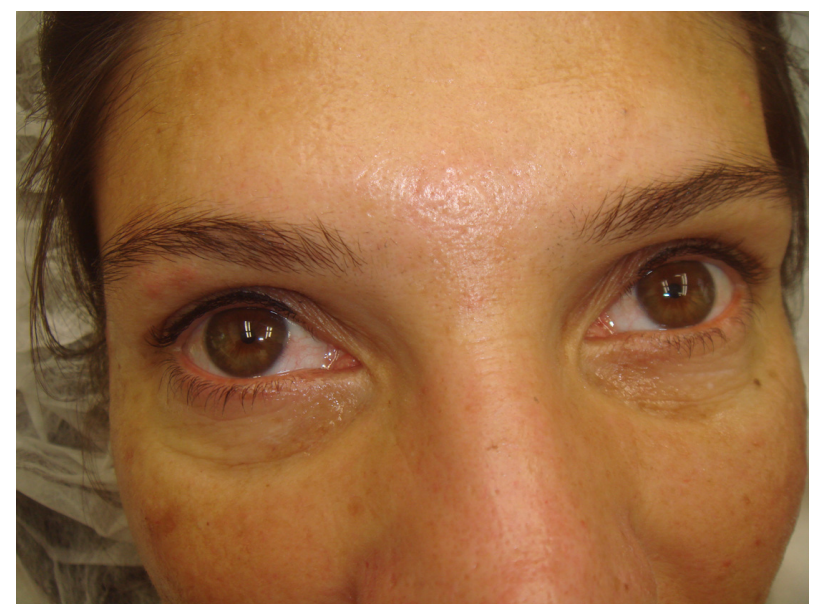

Figure 3B Monopolar radiofrequency treatment of lower eyelids after two treatments every other week.

\section{Hyperkinetic facial wrinkles}

The major areas with facial wrinkles in the third decade of life are the forehead (frontalis muscle) and glabella (corrugator muscles). The most evidence-based data are available for the use of botulinum toxin type A. There are three approved products on the German market (from A to Z): Azzalure (Galderma, Paris, France/Medicis Aesthetics, Scottsdale, AZ), Bocouture (Merz, Frankfurt, Germany), and Vistabel (Allergan, Irvine, CA).

Both large multicenter trials and postmarketing surveillance clearly demonstrate that these drugs are safe and effective. There is no tachyphylaxis after repeated application. Adverse effects are mild and temporary as long as contraindications are not ignored. Injection pain and bruising may occur, others such as brow ptosis are mainly due to incorrect injection technique and are reduced by improved technique. ${ }^{23-25}$

Table I Improvement of skin laxity by radiofrequency

\begin{tabular}{|c|c|c|}
\hline Methods/devices & Best outcome & References \\
\hline $\begin{array}{l}\text { Bipolar radiofrequency } \\
\text { system }\end{array}$ & $\begin{array}{l}5 \%-15 \% \\
\text { improvement of } \\
\text { facial skin elasticity }\end{array}$ & Willey et $\mathrm{al}^{40}$ \\
\hline $\begin{array}{l}\text { Fractional radiofrequency } \\
\text { system bipolar }\end{array}$ & $\begin{array}{l}\text { I6\% improvement } \\
\text { in facial skin laxity } \\
\text { scoring }\end{array}$ & $\begin{array}{l}\text { Alexiades- } \\
\text { Armenakas } \\
\text { et } \mathrm{al}^{4 \mathrm{I}}\end{array}$ \\
\hline $\begin{array}{l}\text { Monopolar radiofrequency } \\
\text { system }\end{array}$ & $\begin{array}{l}\text { Improvement in } \\
\text { overall appearance }\end{array}$ & Bogle et $\mathrm{al}^{42}$ \\
\hline $\begin{array}{l}\text { Intense pulsed optical energy } \\
\text { and conducted bipolar } \\
\text { radiofrequency }\end{array}$ & $\begin{array}{l}\text { Subjective } \\
\text { improvement in } \\
89.5 \% \text { of subjects }\end{array}$ & Yu et $\mathrm{al}^{43}$ \\
\hline $\begin{array}{l}\text { Intense pulsed optical energy } \\
\text { and conducted bipolar } \\
\text { radiofrequency }\end{array}$ & $\begin{array}{l}62.9 \% \text { improvement } \\
\text { in facial skin laxity } \\
\text { scoring }\end{array}$ & Sadick et $\mathrm{al}^{44}$ \\
\hline $\begin{array}{l}\text { Combined radiofrequency } \\
\text { and diode laser system }\end{array}$ & $\begin{array}{l}\text { Clinically modest } \\
\text { improvement }\end{array}$ & $\begin{array}{l}\text { Doshi and } \\
\text { Alster }{ }^{45}\end{array}$ \\
\hline
\end{tabular}


The effects will last between five to six months with some interindividual variability. For advanced glabellar lines combining with a nonpermanent filler such as crosslinked HA gives longer lasting improvement. Recently, we described a new injection technique to correct the downturn of the corners of the mouth with botulinum toxin type A. We used a combination of platysma and depressor anguli oris modification by partial chemical denervation. ${ }^{26}$

\section{Fillers for younger skin}

The use of dermal fillers has expanded over the last two decades. The major indication is volumizing and sculpturing (Figure 4). Fillers can be used in younger females although the indications and products preferred may differ from those in more mature females.

Small amounts of fillers may be useful in the correction of glabellar folds as mentioned earlier. Laterally placed filler in a fanning technique may be used to enhance the brows. Occasional minor irregularities may occur, but these can be smoothed out by massage or blended by further injection. Results lasting between six months and two years are reported depending on the type of filler. Some brow configurations that falsely project emotional states, such as anxiety, may also be corrected. ${ }^{27}$

Liquid lift of the middle and lower face is realized by deep, periostal placement of higher crosslinked monophasic HA fillers in the cheekbone area. By this placement, the filler depot has a longer durability compared to nasolabial folds or cheeks because of the limited movements in this region. There is also a mild effect on upper lip position. ${ }^{28}$ In nasolabial fold treatment, biodegradable microparticle injectables, including Radiance (BioForm, San Mateo, CA) or Radiesse (Merz) provide longer lasting results. Microscopically new collagen

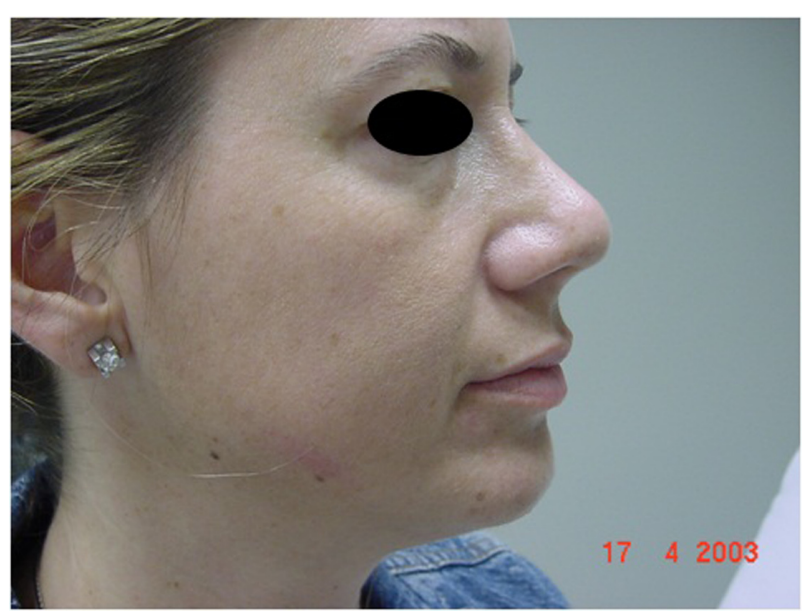

Figure 4A Hyaluronic acid filler for facial sculpturing (midface) before injection.

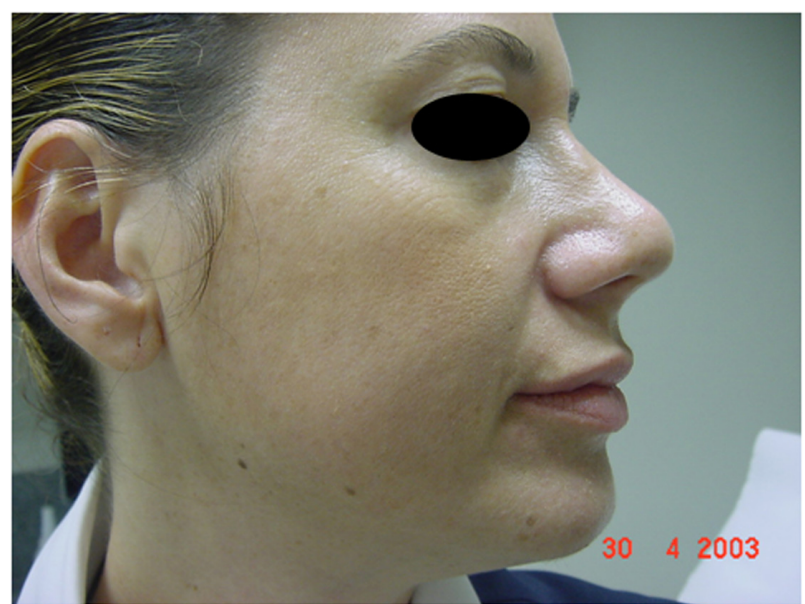

Figure 4B Hyaluronic acid filler for facial sculpturing (midface) two weeks after injection.

formation was observed around the microparticles consisting of calcium hydroxylapetite..$^{29-31}$

Lip contouring by filler injection is often requested. Short-term effects may be favorable when soft HA fillers are placed along the vermillion border to underline the upper lip. The Cupid's bow should not be touched. In the case of lip contouring with smaller filler volumes, a cool pack may provide sufficient pain relief. Lip contouring effects may last for three to six months.

Volumizing the lip is a more painful procedure and local anesthetics are recommended. Overtreatment gives an unnatural look and increases the risk of adverse effects such as granuloma formation and others. It is important to investigate the fine motions of the lips before treatment. Filler placement should not result in a loss of such fine movements to avoid an artificial touch perceived by others. As skin laxity becomes more prominent, lip volumizing creates not only additional volume but also weight. This can lead to less satisfying results. The less the better as a rule. ${ }^{31}$

Indications of lip volumizing by fillers in young females may be genetically thin lips and posttraumatic irregularities. A tool for objective evaluation of the individual situation and the enhancement by filler is the lip index. Adding upper and lower lip indices resulted in the overall lip index, which was found to be approximately 50 in average females of Caucasian descent, about 100 in females of Asian descent, and nearly 200 in females of African descent. ${ }^{28}$ It is noteworthy, that volumizing treatment of nasolabial folds and cheeks can result in an improvement in upper lip position. ${ }^{1,2}$

Partial or whole face injection with uncrosslinked HA gels to provide a rapid but temporary improvement of skin smoothness and hydration is performed by syringes and other technical devices as part of mesotherapy. Long-term 
outcome has not been analyzed scientifically. Nevertheless, the combination of multiple punctures with HA injection leads to a mild oedema and may induce dermal wound healing responses but further studies are needed. ${ }^{32}$

\section{Aesthetic procedures to correct piercing and piercing complications}

While earlobe piercing has been socially and widely accepted for females over many decades, body piercing has not. Recently body piercing has become very popular in young adults, in particular young women. The prevalence of body piercing in the UK is $10 \%$. Nearly half the women aged 16-24 reported having had a piercing. ${ }^{33}$ In a US survey, $14 \%$ of adults had body piercings. Body piercing was more common among women. Local medical complications were present in one-third of those with body piercings. ${ }^{34}$ The situation is comparable to other Western countries. ${ }^{35}$ Complications of these body modifying procedures often warrant medical treatment (Figures 5 and 6).

Reconstruction of earlobes and other parts after piercing is being increasingly requested by patients. A more common problem with earlobe piercing is the development of keloids. There seems to be a genetic background for the risk of keloid formation. Permanent clearing of keloids is not simple. Stahl et $\mathrm{al}^{36}$ used the "sandwich" technique protocol with extralesional excision and external-beam radiotherapy given a day before and a day after the operation. In a retrospective evaluation of their patients (average age 24 years; $57 \%$ males), recurrence rates were $25 \%$ and $27 \%$ for low- and high-risk patients, respectively. Overall, patient satisfaction was high.

Incomplete earlobe clefts are another possible complication of piercing and the wearing of jewellery in this area. There are

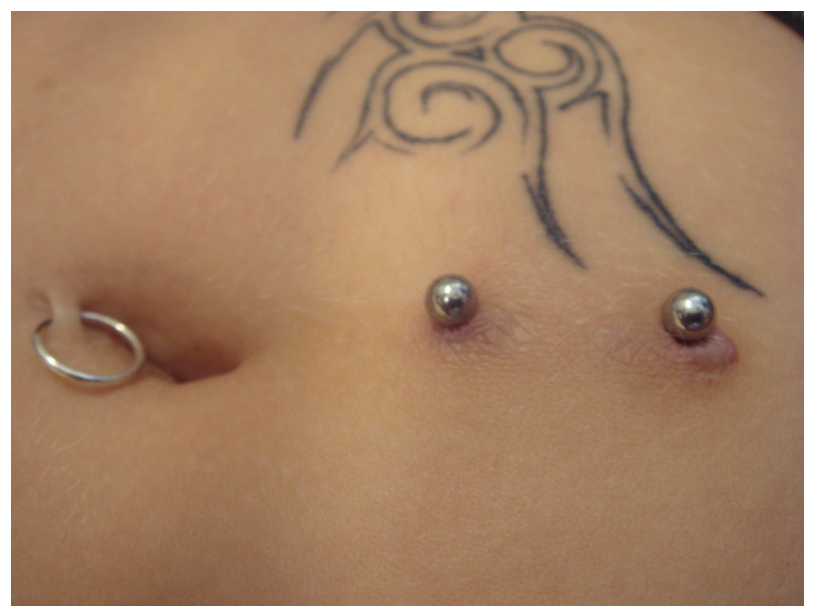

Figure 5 Piercing, tunnelling and tattoo in a 24-year-old female. Skin inflammation at the tunnelling site.

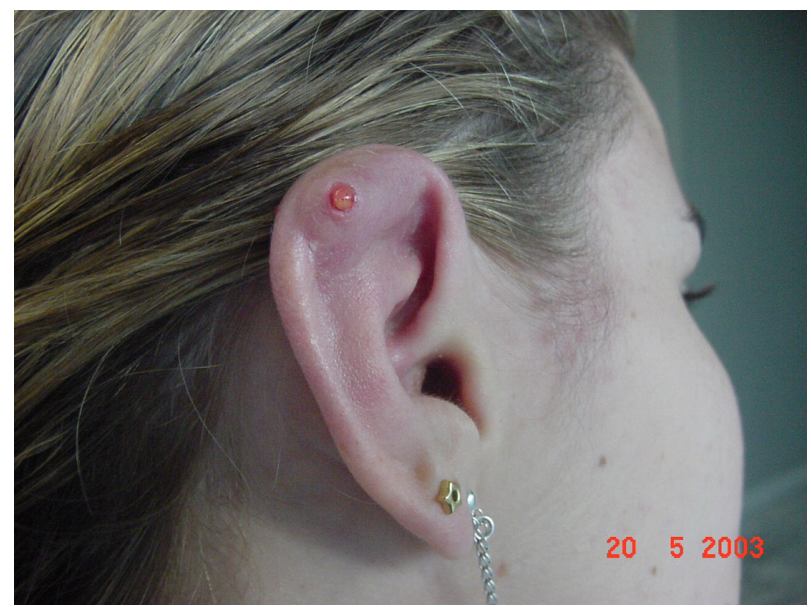

Figure 6A Cartilage destruction after piercing due to an inflammatory reaction.

surgical and nonsurgical procedures available to deal with this problem. Brazilian authors presented a nonsurgical procedure for incomplete earlobe cleft repair using trichloroacetic acid $90 \%$. They assessed 32 patients with a total of 53 earlobes to be noninvasively repaired. The complete treatment varied from 2 to 50 days with repeated application of trichloroacetic acid $90 \%$. No recurrences were observed during one year of follow-up. All of the clefts were totally repaired, and all

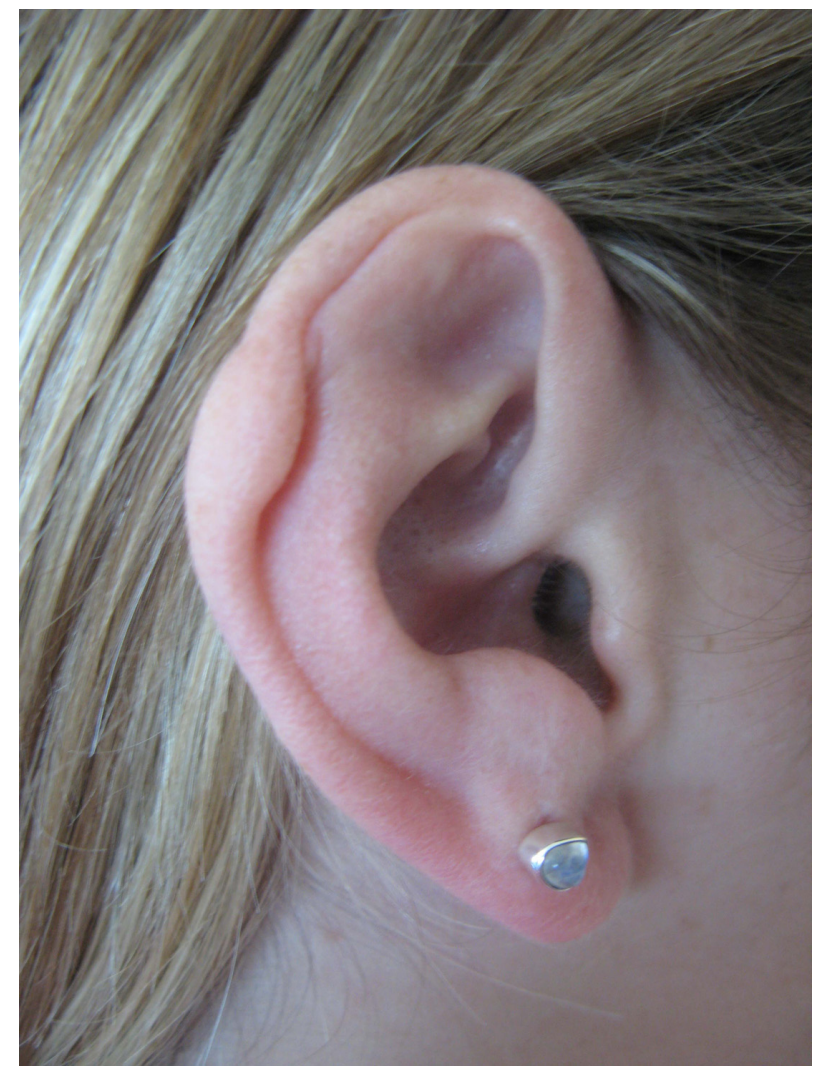

Figure 6B Seven years later with destruction of helical cartilage. 


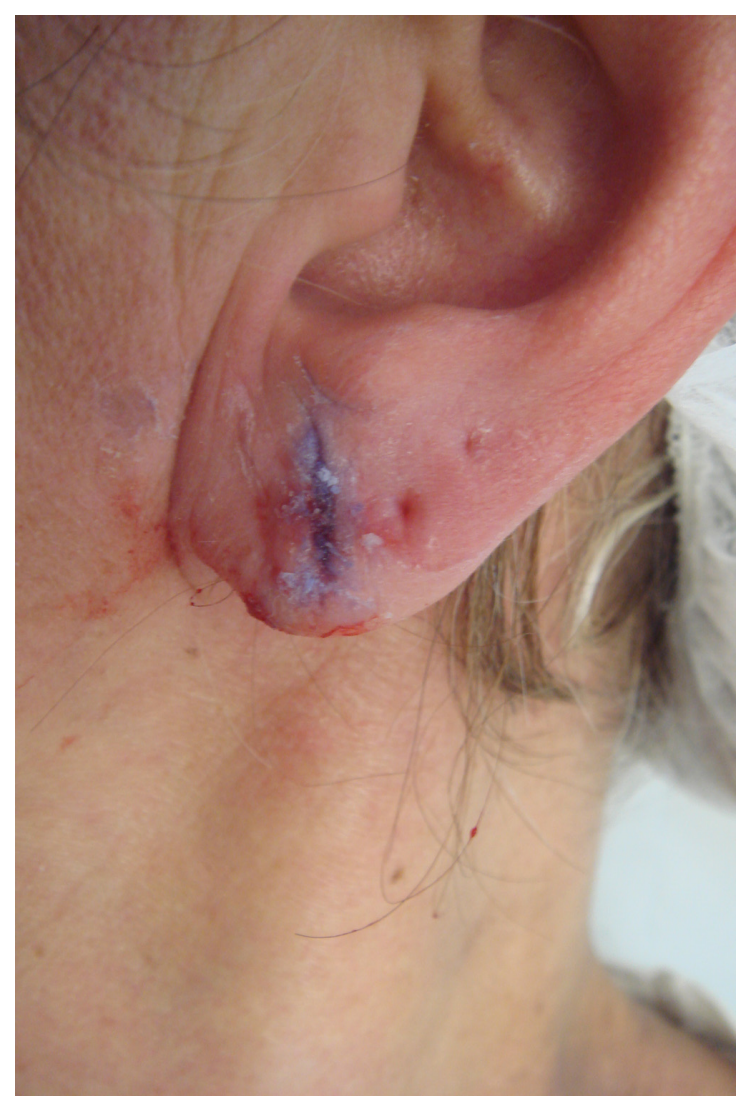

Figure 7 Reconstruction of an earlobe defect by removal of the epithelium by radiosurgery and appliation of acrylic tissue glue.

of the patients were satisfied with the aesthetic results. The procedure resulted in good functional and cosmetic results, with low costs, minimum risks, and was easy to apply. ${ }^{37}$

Another option is the excision of the epithelium by radiofrequency and immediate application of acrylatebased tissue glue (Figure 7). Many surgical techniques have been described for the correction of ear lobe clefts, such as direct suturing, zetaplasty, ritidoplasty with ear lobe correction, V-shaped flaps, L-shaped flaps, and "surgery of the ear ring". 38

\section{Conclusion}

Patients in their third decade of life can benefit from minimally aesthetic procedures either to delay minor signs of facial aging or to repair acquired disfigurements. Identification of those patients who suffer from body dysmorphic disorder and psychiatric illness is important. Careful communication to patients about gains and risks is of the greatest importance. Furthermore, overtreatment should be avoided. A natural look is of particular importance for this age group. Aesthetic medical procedures are considered an integral part of ethical medicine, not, as suggested by mass media, a part of fashion. ${ }^{39}$

\section{Disclosure}

No conflicts of interest were declared in relation to this paper.

\section{References}

1. Wollina U, Payne CR. Ageing well - the role of minimally invasive aesthetic dermatological procedures in women over 65. J Cosmet Dermatol. 2010;9(1):50-58.

2. Goldman A, Wollina U. Facial rejuvenation for middle-aged women: a combined approach with minimally invasive procedures. Clin Interv Aging. 2010:5:293-299.

3. Wollina U. Addiction to tanning - a new cause of early onset of nonmelanoma skin cancer. Open Dermatol J. 2009;3:86-88.

4. Jansen T, Podda M. Therapy of acne scars. J Dtsch Dermatol Ges. 2010;8(Suppl 1):S81-S88.

5. Lee JW, Kim BJ, Kim MN, Lee CK. Treatment of acne scars using subdermal minimal surgery technology. Dermatol Surg. 2010;36(8): 1281-1287.

6. Manuskiatti W, Triwongwaranat D, Varothai S, Eimpunth S, Wanitphakdeedecha R. Efficacy and safety of a carbon-dioxide ablative fractional resurfacing device for treatment of atrophic acne scars in Asians. J Am Acad Dermatol. 2010;63(2):274-283.

7. Kutlubay Z, Gokdemir G. Treatment of atrophic facial acne scars with the Er:YAG laser: a Turkish experience. $J$ Cosmet Laser Ther. 2010; 12(2):65-72.

8. Wollina U. Capryloyl salicylic acid (CSA) peel for acne and actinic damage. Kosmet Med. 2009;30(4):142-145.

9. Garg VK, Sinha S, Sarkar R. Glycolic acid peels versus salicylicmandelic acid peels in active acne vulgaris and post-acne scarring and hyperpigmentation: a comparative study. Dermatol Surg. 2009;35(1): 59-65.

10. Kempiak SJ, Uebelhoer N. Superficial chemical peels and microdermabrasion for acne vulgaris. Semin Cutan Med Surg. 2008; 27(3):212-220.

11. Prignano F, Campolmi $\mathrm{P}$, Bonan $\mathrm{P}$, et al. Fractional $\mathrm{CO}_{2}$ laser: a novel therapeutic device upon photobiomodulation of tissue remodelling and cytokine pathway of tissue repair. Dermatol Ther 2009;22(Suppl):S8-S15.

12. Mahmoud BH, Srivastava D, Janiga JJ, Yang JJ, Lim HW, Ozog DM. Safety and efficacy of erbium-doped yttrium aluminum garnet fractionated laser for treatment of acne scars in type IV to VI skin. Dermatol Surg. 2010;36(5):602-609.

13. Cho SB, Lee SJ, Kang JM, Kim YK, Chung WS, Oh SH. The efficacy and safety of 10,600-nm carbon dioxide fractional laser for acne scars in Asian patients. Dermatol Surg. 2009;35(12):1955-1961.

14. Epstein RE, Spencer JM. Correction of atrophic scars with artefill: an open-label pilot study. J Drugs Dermatol. 2010;9(9):1062-1064.

15. Kim HJ, Kim TG, Kwon YS, Park JM, Lee JH. Comparison of a 1,550 nm erbium: glass fractional laser and a chemical reconstruction of skin scars (CROSS) method in the treatment of acne scars: a simultaneous split-face trial. Lasers Surg Med. 2009;41(8): $545-549$.

16. Wanitphakdeedecha R, Manuskiatti W, Siriphukpong S, Chen TM. Treatment of punched-out atrophic and rolling acne scars in skin phototypes III, IV, and V with variable square pulse erbium: yttriumaluminum-garnet laser resurfacing. Dermatol Surg. 2009;35(9): $1376-1383$.

17. Fabbrocini G, Fardella N, Monfrecola A, Proietti I, Innocenzi D. Acne scarring treatment using skin needling. Clin Exp Dermatol. 2009;34(8): 874-849.

18. Balighi K, Robati RM, Moslehi H, Robati AM. Subcision in acne scar with and without subdermal implant: a clinical trial. J Eur Acad Dermatol Venereol. 2008;22(6):707-711.

19. Ortiz AE, Tremaine AM, Zachary CB. Long-term efficacy of a fractional resurfacing device. Lasers Surg Med. 2010;42(2):168-170. 
20. Bhardwaj D, Khunger N. An assessment of the efficacy and safety of cross technique with $100 \%$ TCA in the management of ice pick acne scars. J Cutan Aesth Surg. 2010;3(2):93-96.

21. Sadick N. Tissue tightening technologies: fact or fiction. Aesthet Surg J. 2008;28(2):180-188.

22. Monica E. Periorbital skin tightening with a broadband infrared device: preliminary study results. J Cosmet Laser Ther. 2010;12(1):38-41.

23. Hevia O. Retrospective review of 500 patients treated with abobotulinumtoxin A. J Drugs Dermatol. 2010;9(9):1081-1084.

24. Rubin M, Dover J, Maas C, Nestor M. An analysis of safety data from five phase III clinical trials on the use of botulinum neurotoxin type A-ABO for the treatment of glabellar lines. Aesthet Surg J. 2009; 29(6 Suppl):S50-S56.

25. Cohen JL, Schlessinger J, Cox SE, Lin X; Reloxin Investigational Group. An analysis of the long-term safety data of repeat administrations of botulinum neurotoxin type A-ABO for the treatment of glabellar lines. Aesthet Surg J. 2009;29(6 Suppl):S43-S49.

26. Goldman A, Wollina U. Elevation of the corner of the mouth using botulinum toxin type A. J Cutan Aesthet Surg. 2010;3(3):145-150.

27. Lambros V. Volumizing the brow with hyaluronic acid fillers. Aesthet Surg J. 2009;29(3):174-179.

28. Wollina U, Goldman A, Berger U, Abdel-Naser MB. Esthetic and cosmetic dermatology. Dermatol Ther. 2008;21(2):118-130.

29. Tzikas TL. Evaluation of Radiance FN soft tissue filler for facial soft tissue augmentation. Arch Facial Plast Surg. 2004;6(4):234-239.

30. Moers-Carpi M, Vogt S, Santos G, Planas J, Vallve S, Howell D. A multicenter randomized trial comparing calcium hydroxlyapetite to two hyaluronic acids for the treatment of nasolabial folds. Dermatol Surg. 2007;33(Suppl 2):S144-S151.

31. Newman J. Review of soft tissue augmentation in the face. Clin Cosmet Investig Dermatol. 2009;2:141-150.

32. Atiyeh BS, Ibrahim AE, Dibo SA. Cosmetic mesotherapy: between scientific evidence, science fiction, and lucrative business. Aesthetic Plast Surg. 2008;32(6):842-849.

33. Lemperle G, Anderson R, Knapp TR. An index for quantitative assessment of lip augmentation. Aesthet Surg J. 2010;30(3):301-310.

34. Bone A, Ncube F, Nichols T, Noah ND. Body piercing in England: a survey of piercing at sites other than earlobe. BMJ. 2008;336(7658): 1426-1428.
35. Laumann AE, Derick AJ. Tattoos and body piercings in the United States: a national data set. J Am Acad Dermatol. 2006;55(3):413-421.

36. Stahl S, Barnea Y, Weiss J, et al. Treatment of earlobe keloids by extralesional excision combined with preoperative and postoperative "sandwich" radiotherapy. Plast Reconstr Surg. 2010;125(1): 135-141.

37. De Mendonça MC, de Oliveira AR, Araújo JM, Silva MG, Gamonal A. Nonsurgical technique for incomplete earlobe cleft repair. Dermatol Surg. 2009;35(3):446-450.

38. Patrocínio LG, Morais RM, Pereira JE, Patrocínio JA. Earlobe cleft reconstructive surgery. Braz J Otorhinolaryngol. 2006;72(4): $447-451$.

39. Gadebusch Bondio M. Medical aesthetics [German]. Wilhelm Fink Verlag, Munich, 2005.

40. Willey A, Kilmer S, Newman J, et al. Elastometry and clinical results after bipolar radiofrequency treatment of skin. Dermatol Surg. 2010; 36(6):877-884.

41. Alexiades-Armenakas M, Rosenberg D, Renton B, Dover J, Arndt K. Blinded, randomized, quantitative grading comparison of minimally invasive, fractional radiofrequency and surgical face-lift to treat skin laxity. Arch Dermatol. 2010;146(4);396-405.

42. Bogle MA, Ubelhoer N, Weiss RA, Mayoral F, Kaminer MS. Valuation of the multiple pass, low fluence algorithm for radiofrequency tightening of the lower face. Lasers Surg Med. 2007;39(3):210-217.

43. Yu CS, Yeung CK, Shek SY, Tse RK, Kono T, Chan HH. Combined infrared light and bipolar radiofrequency for skin tightening in Asians. Lasers Surg Med. 2007;39(6):471-475.

44. Sadick NS, Alexiades-Armenakas M, Bitter P Jr, Hruza G, Mulholland RS. Enhanced full-face skin rejuvenation using synchronous intense pulsed optical and conducted bipolar radiofrequency energy (ELOS): introducing selective radiophotothermolysis. J Drugs Dermatol. 2005; 4(2):181-186.

45. Doshi SN, Alster TS. Combination radiofrequency and diode laser for treatment of facial rhytides and skin laxity. J Cosmet Laser Ther. 2005; $7(1): 11-15$
Clinical, Cosmetic and Investigational Dermatology

\section{Publish your work in this journal}

Clinical, Cosmetic and Investigational Dermatology is an international, peer-reviewed, open access, online journal that focuses on the latest clinical and experimental research in all aspects of skin disease and cosmetic interventions. All areas of dermatology will be covered; contributions will be welcomed from all clinicians and

\section{Dovepress}

basic science researchers globally. This journal is indexed on CAS The manuscript management system is completely online and includes a very quick and fair peer-review system, which is all easy to use. Visit http://www.dovepress.com/testimonials.php to read real quotes from published authors. 